\title{
Rede óptica passiva usando TDM e WDM
}

\author{
José Ewerton P. de Farias, Júlio César M. Diniz e Luis H. H. de Carvalho
}

\begin{abstract}
Resumo - Este artigo apresenta uma revisão sobre as alternativas tecnológicas atuais para a opticalização das redes de acesso. Apresenta também alguns resultados de uma investigação sobre uma arquitetura híbrida para as redes ópticas de acesso de segunda geração usando multiplexação por divisão no tempo (TDM) e em comprimento de onda (WDM). Indicadores de desempenho dos enlaces ópticos na direção redeusuários (downstream) são usados para a determinação da qualidade do serviço, e do alcance da rede, isto é, distância máxima entre instalações da operadora de telecomunicações e dependências de usuários.
\end{abstract}

Palavras-chaves - Redes ópticas de acesso, redes ópticas passivas, TDM-WDM-PON.

\section{INTRODUÇÃO}

As redes ópticas de acesso ora em implantação em várias regiões terão que se mostrar viáveis economicamente, além de propiciarem os benefícios sociais esperados com a eliminação (ou quase eliminação) do conhecido "gargalo" atualmente existente nos últimos 1.000-1.500 metros entre a operadora de telecomunicações e as dependências dos usuários. Velocidades de acesso da ordem de algumas dezenas de Mbps são esperadas para usuários residenciais nos próximos anos [1]. Essas novas redes ópticas de acesso deverão ser capazes de suportar uma ampla gama de serviços, entre os quais: (i) Serviço triplo (voz, dados e TV); (ii) Vídeo sob demanda; (iii) Vídeoconferência; (iv) Compartilhamento de arquivos de áudio e vídeo entre pares de pessoas; (v) TV em alta definição multicanal; (vi) Jogos multi-parceiros online; (vii) Telemedicina; (viii) Trabalho remoto; (ix) Telesupervisão, etc.

Essa multiplicidade de demandas exige uma maior velocidade de conexão ou, equivalentemente, maior largura de banda. Para atender a tais necessidades, alguns padrões de redes ópticas de acesso foram desenvolvidos. Hoje, após cerca de 25 anos sendo considerada a tecnologia do futuro para as redes de acesso, a infra-estrutura FTTH (Fibra óptica até as residências), principalmente na forma de redes ópticas passivas (PONs - do inglês Passive Optical Networks), está sendo implantada em larga escala na Ásia [2] e nos Estados Unidos [3], e com menor rapidez na Europa [4]. Em fevereiro de 2009 haviam 13,2 milhões de usuários FTTH no Japão, 6,05 milhões nos Estados Unidos, 5,96 milhões na China e

José Ewerton P. de Farias, Júlio César M. Diniz e Luis Henrique H. de Carvalho, Depto. de Engenharia Elétrica, Universidade Federal de Campina Grande, Campina Grande, Brasil, E-mails: ewerton@ieee.org, julio.diniz@ee.ufcg.edu.br, luis.carvalho@ee.ufcg.edu.br. Este trabalho foi parcialmente financiado pela Fundação $\mathrm{CPqD}$, através do Contrato $\mathrm{CPqD}-$ PaqTcPB No. 2699.
2,4 milhões na Europa. As economias asiáticas continuam a superar o resto do mundo em termos da penetração de FTTH no mercado. Na Coréia do Sul, $44 \%$ das residências estão conectadas. Em Hong Kong, 28\%. No Japão 27\%. Em Taiwan, 12\% [5]. O governo da Índia estabeleceu a meta de 20 milhões de usuários FTTH para o ano 2010 [6].

Em uma rede óptica passiva, os componentes localizados fora das dependências da operadora de telecomunicações e das dependências dos usuários são todos passivos, não exigindo alimentação elétrica. A escolha de uma dessas alternativas depende dos tipos de serviços pretendidos e dos custos de implantação e de manutenção da infra-estrutura.

Para a primeira geração de PONs, uma implantação econômica foi o aspecto determinante no desenvolvimento das tecnologias. Por isso, foram padronizadas PONs usando uma topologia em árvore e com protocolo de controle de acesso ao meio (protocolo MAC) baseado em TDMA (múltiplo acesso por divisão do tempo). Os padrões atuais de TDM-PONs especificam taxas de transmissão de até 2,5 Gbps com alcance máximo de $20 \mathrm{~km}$ ou mais. Tais especificações satisfazem às necessidades de acesso de faixa larga para usuários residenciais neste momento histórico.

Neste artigo é descrita e avaliada uma arquitetura de uma PON híbrida, usando TDM e WDM. Essa solução combina abundância de largura de faixa e expansibilidade, características de WDMA (acesso múltiplo WDM), com simplicidade e baixos custos inerentes ao TDMA (acesso múltiplo TDM). Na seção II é feita uma breve revisão das arquiteturas FTTH usando TDM-PON. A seção III apresenta uma discussão sobre PONs usando a solução híbrida TDMWDM. Resultados de simulações para uma TDM-WDMPON com 32 usuários são apresentados na seção IV. Finalmente, na seção V são incluídas as conclusões.

\section{ALTERNATIVAS PARA REDES ÓPTICAS PASSIVAS}

O compartilhamento da fibra óptica e o baixo custo de manutenção são as duas principais razões para a implantação de PONs. Diferentes métodos de multiplexação podem ser aplicados sobre uma arquitetura de PON, entre os quais TDM e WDM. Os protocolos ATM (Asynchronous Transfer Mode) e Ethernet foram incorporados em padrões denominados de APON (ou ATM-PON), BPON (Broadband PON), EPON (Ethernet PON), GPON (Gigabit-capable PON) [7]-[10], WDM-PON, [12]-[15] e 10GEPON (10 Gbit/s EPON) [16].

Uma arquitetura ponto-a-multiponto facilita o manuseio da rede e diminui custos operacionais. Nas dependências da operadora de telecomunicações há um TLO (Terminal de Linha Óptica) que gerencia a comunicação dos usuários. Nas dependências dos usuários há uma URA (Unidade de Rede de 
Acesso) que converte o sinal óptico em sinal elétrico portador de tráfegos diversos, tais como, TV, dados, voz, etc. O esquema dessa arquitetura é ilustrado na Fig. 1.

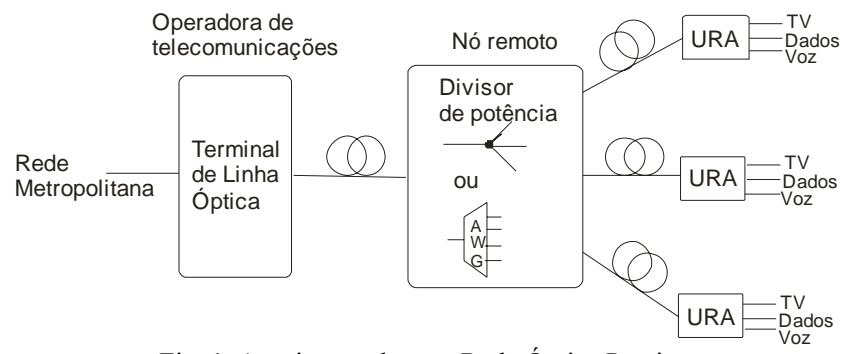

Fig. 1. Arquitetura de uma Rede Óptica Passiva.

Usando a arquitetura da Fig. 1, duas estratégias de acesso múltiplo à fibra óptica compartilhada podem ser implementadas: TDM-PON (Multiplexação por Divisão do Tempo) e WDM-PON (Multiplexação por Divisão em Comprimento de Onda). Em acesso múltiplo TDM cada usuário pode usar toda a largura de banda de transmissão durante janelas de tempo reservadas. Para conectar os usuários à fibra óptica é usado um divisor de potência óptica no nó remoto. Com a finalidade de gerenciar a transmissão de mensagens e possibilitar o compartilhamento da largura de faixa na direção URAs $\rightarrow$ TLO, um protocolo eficiente para controle de acesso ao meio (MAC) é necessário. A escolha do algoritmo a ser usado é uma das chaves para se fazer um sistema TDMA eficiente. Uma importante característica do TDMA é que quando um cliente não precisa enviar dados, ou está enviando dados em menor quantidade, o tempo dedicado a ele diminui e o tempo dedicado a outro usuário que esteja enviando mais dados é aumentado automaticamente. Esta estratégia é conhecida alocação dinâmica de largura de faixa (DBA). O uso de DBA aumenta a eficiência de uma estrutura PON quando os clientes são não uniformes, porém quando a demanda pela largura de banda passa a ser alta, DBA pode limitar a qualidade do serviço (QoS).

Conforme mencionado anteriormente, há várias tecnologias para redes ópticas passivas usando TDM: A/BPON, GPON e EPON. Tais tecnologias estão padronizadas pelas normas ITU-T G.983, ITU-T G.984 e IEEE 802.3ah, respectivamente. Além desses padrões, a norma IEEE 802.3av (10GEPON) [16] encontra-se em vias de aprovação final neste momento. A norma da tecnologia APON visava inicialmente aplicações residenciais e em sua primeira versão não incluía suporte a fornecimento de serviços de vídeo através da rede óptica. Tempo depois, como estratégia de mercado, o nome APON foi modificado para BPON, sendo apenas uma versão aprimorada da APON. Baseando-se nas normas de APON da ITU-T, o IEEE lançou a EPON, como uma tentativa de entregar dados, vídeo e voz através de uma só rede de acesso. Já a GPON é a segunda geração do protocolo publicada pela ITU, sendo aberto a reconsiderações para garantir suporte a múltiplos serviços e expansibilidade, além de simplicidade para administração, manutenção e provisionamento. Uma análise comparativa dos desempenhos de EPON, APON e GPON é encontrada em
[10], enquanto que aspectos da implantação otimizada de infra-estruturas FTTH são discutidos em [11].

\section{REDES ÓPTICAS PASSIVAS COM WDM}

À medida que novas aplicações de faixa larga aparecerem, as demandas dos usuários tenderão a ultrapassar a capacidade da primeira geração de redes ópticas de acesso (TDM-PON), e estas precisarão ser atualizadas. Uma atualização baseada em WDM parece ser uma evolução natural, uma vez que não exige uma mudança radical na infra-estrutura de fibras. Com WDM pode-se implementar enlaces virtuais ponto-a-ponto sobre uma PON sem o uso de protocolos MAC complicados, o que simplifica a gerência da rede, a proteção e a segurança.

Em geral, WDM-PON é uma tecnologia extremamente eficiente, e à prova de futuro, para uso em redes de acesso e metropolitanas [12]-[15]. Permitindo uso altamente eficiente da infra-estrutura de fibra óptica, e conectividade ponto-aponto para múltiplos locais remotos através de uma única fibra, conforme ilustrado na Fig. 2. As WDM-PONs possuem arquitetura de uso flexível que podem servir a muitas aplicações, tanto para usuários comerciais, quanto para usuários residenciais. Tal funcionalidade é possível desde que cada usuário final esteja conectado à operadora de telecomunicações através de um canal óptico bidirecional dedicado. Assim, este ponto-a-ponto virtual permite grandes larguras de faixa garantidas, independência de taxa de transmissão, transparência de protocolo, fácil atualização, alta qualidade de serviço (QoS), segurança e privacidade muito melhores que as possíveis com TDM-PON.

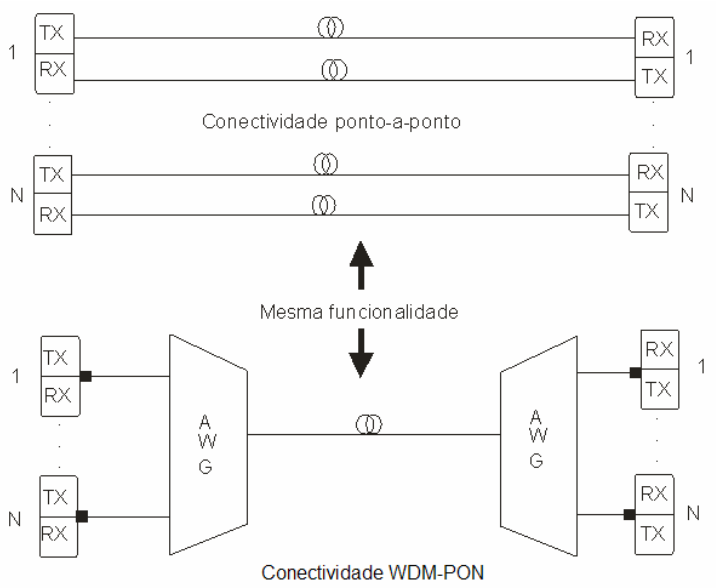

Fig. 2. Arquitetura ponto-a-ponto e WDM-PON.

Para se fazer uma conexão ponto-a-ponto dedicada para $\mathrm{N}$ locais remotos, necessitamos de $\mathrm{N}$ transceptores tanto na operadora de telecomunicações quanto nos locais remotos das URAs. Normalmente, usaríamos $2 \mathrm{~N}$ fibras para termos tal funcionalidade. $\mathrm{Na}$ arquitetura WDM-PON, estas $2 \mathrm{~N}$ fibras são substituídas por uma única fibra que conectará todos os $2 \mathrm{~N}$ transmissores através de multiplexação e demultiplexação por comprimento de onda, ou seja, cada fibra é substituída por um comprimento de onda dedicado. 
A tecnologia TDM utiliza um único transceptor de alto desempenho compartilhado na operadora de telecomunicações para comunicar com os $\mathrm{N}$ transceptores remotos das URAs Desde que cada URA utiliza o mesmo comprimento de onda na direção usuários-rede (upstream), eles devem usar janelas de tempo variáveis e dedicadas, onde apenas uma URA pode transmitir por vez.

Embora uma TDM-PON diminua em muito o número necessário de componentes ópticos, ela faz isso em troca de um desempenho mais modesto. Existe uma penalidade de aproximadamente $1 / \mathrm{N}^{2}$ no orçamento de potência da rede. Esta penalidade origina-se parte no divisor de potência óptica e parte devido ao fato de que a largura de faixa de ruído no receptor ser $\mathrm{N}$ vezes a taxa média de dados em cada URA. A complexidade do algoritmo necessário para se garantir a QoS para todos os $\mathrm{N}$ usuários cresce com $\mathrm{N}$.

Tais problemas não estão presentes em uma WDM-PON. Ao invés de divisores de potência, utiliza-se um multiplexador WDM, que pode ser baseado em AWG (Arrayed Wavelength Grating), a perda devido à canalização pode ser muito pequena (essencialmente perda por inserção da ordem de 3-6 dB para dispositivos no mercado). Também, desde que WDM garante conexões ópticas ponto-a-ponto, a penalidade do ruído do receptor não existe desde que a largura de faixa de cada receptor é apenas aquela necessária para a sua taxa de transmissão. E em relação a QoS, desde que se possa ter conectividade ponto-a-ponto entre usuários finais, não existem problemas quanto à qualidade do serviço, já que os usuários estão desvinculados dos outros que compartilham a rede óptica.

TABELA I. Comparação entre ponto-a-ponto, TDM-PON e WDM-PON

\begin{tabular}{llll}
\hline & Capacidade & Custo & Atualização \\
\hline Ponto-a-Ponto & Superior & Altíssimo & Fácil \\
TDM-PON & Boa & Baixo & Difícil \\
WDM-PON & Melhor & Alto & Fácil \\
\hline
\end{tabular}

\section{SIMULAÇÕES COM A SOLUÇÃO HÍBRIDA TDM-WDM-PON}

Utilizou-se a plataforma OptiSystem 7.0 da OptiWave Inc. $^{\text {TM }}$. É ilustrada na Fig. 3 a arquitetura TDM-WDM-PON utilizada nas simulações. Considera-se apenas o tráfego na direção rede-usuários (downstream). A rede conecta 32 fontes de dados a 32 usuários, por meio de uma única fibra. Os fluxos de cada 4 usuários serão combinados via TDM e então os 8 fluxos TDM serão multiplexados usando WDM. Deseja-se determinar a distância máxima entre as fontes de dados, localizadas nas dependências da operadora de telecomunicações, e as dependências dos usuários. A qualidade do enlace fonte de dados-usuário, medida quantitativamente através da BER (taxa de erro de bit) ou qualitativamente pela observação do diagrama do olho, é usada como critério para limitar o alcance da rede.

Cada fonte de dados faz parte de um bloco transmissor (região sombreada na Fig. 3). Por sua vez, tal bloco é constituído do seguinte:

(i) Fonte de dados (gerador de seqüências pseudoaleatórias) com taxa variável; (ii) Laser de Fabry-Pérot com freqüência de $(193,0+\mathrm{k}$ $0,1) \mathrm{THz}$, onde $\mathrm{k}=1,2, \ldots, 8$ e potência de 2,5 $\mathrm{mW}$.

(iii) Codificador de linha, que transforma a saída da fonte de dados em uma seqüência de pulsos elétricos no formato RZ (Return to Zero).

(iv) Modulador externo do tipo Mach-Zehnder, com perda de inserção de aproximadamente $3,0 \mathrm{~dB}$, tendo como entradas as saídas da fonte laser e do codificador de linha.

Cada 4 fluxos individuais que compartilham lasers de mesma freqüência passa por um defasador com defasagens $\tau$, $\tau=0 ; 0,25 \mathrm{~T}_{\mathrm{b}} ; 0,5 \mathrm{~T}_{\mathrm{b}} ; 0,75 \mathrm{~T}_{\mathrm{b}}$, sendo $\mathrm{T}_{\mathrm{b}}$ o tempo de bit. Após isso utiliza-se um combinador óptico (perda de inserção igual a $1 \mathrm{~dB}$ ) para formar o sinal TDM. Em seguida, os 8 sinais TDM são multiplexados em uma única fibra utilizando um AWG 8x1, com os seguintes parâmetros:

(i) Perda de inserção: $5 \mathrm{~dB}$;

(ii) Largura de faixa de cada canal: $75 \mathrm{GHz}$;

(iii) Espaçamento entre canais: $100 \mathrm{GHz}$;

(iv) Freqüência do canal principal: $193,1 \mathrm{THz}$;

(v) Separação entre canais adjacentes: $>30 \mathrm{~dB}$.

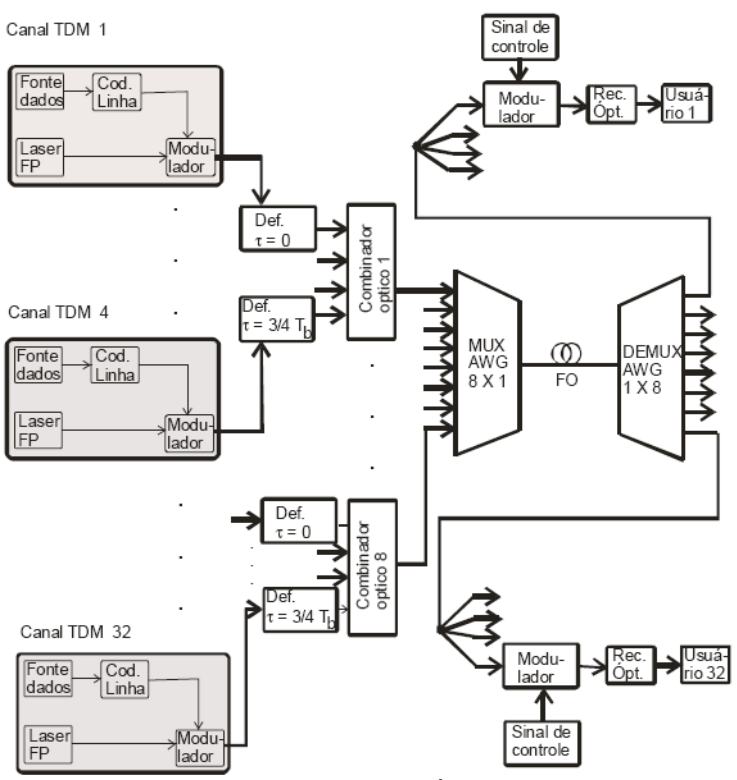

Fig. 3 - Arquitetura da Rede Óptica Passiva simulada.

A fibra utilizada é uma fibra óptica monomodo do tipo DSF (Dispersion Shifted Fiber) com perda de $0,28 \mathrm{~dB} / \mathrm{km}$ na região de comprimentos de onda em torno de $1550 \mathrm{~nm} \mathrm{e}$ demais especificações segundo a norma ITU-T G.653.

O demultiplexador AWG 1x8 utilizado na saída da fibra possui os mesmos parâmetros do multiplexador AWG 8x1. Após ser separado pelo DEMUX AWG, o sinal TDM será a portadora de um modulador Mach-Zehnder, que terá como entrada elétrica um sinal de controle, responsável pela escolha do canal a ser extraído. O canal óptico extraído é então detectado pelo receptor óptico e entregue ao usuário.

Foi medido o desempenho do receptor 1 (193,1 THz e defasamento $\tau=0$ ) para taxas de transmissão de 100 e 30 Mbps e distâncias de propagação variando entre 5 e $20 \mathrm{~km}$. 
Denomina-se receptor 1 aquele nas dependências do usuário 1 (ver Fig. 3).

As Figs. 4, 5, 6 e 7 mostram os diagramas do olho para uma velocidade de acesso individual (downstream) de 100 Mbps e distâncias de 5, 10, 15 e $20 \mathrm{~km}$, respectivamente. As Figs. 8, 9, 10 e 11 mostram os diagramas do olho para uma velocidade de acesso individual (downstream) de $30 \mathrm{Mbps}$ e distâncias de 5, 10, 15 e $20 \mathrm{~km}$, respectivamente. As taxas de erro de bit (BER) são listadas na Tabela II, para todas as combinações de taxa de transmissão e distância simuladas. Em redes ópticas, sabe-se que uma BER aceitável tem ordem de grandeza máxima igual a $10^{-11}$. Segundo tal critério e analisando os dados obtidos, temos que o alcance-limite para uma taxa de transmissão de 100 Mbps é $10 \mathrm{~km}$ e para 30 Mbps é $15 \mathrm{~km}$. Acima dessas distâncias, encontramos valores inaceitáveis para a BER na maioria das aplicações pretendidas.

\begin{tabular}{ccccc}
\multicolumn{5}{c}{ Tabela II. Ordem de grandeza da taxa de erro de bit. } \\
\hline & $5 \mathrm{~km}$ & $10 \mathrm{~km}$ & $15 \mathrm{~km}$ & $20 \mathrm{~km}$ \\
\hline $100 \mathrm{Mbps}$ & $10^{-17}$ & $10^{-11}$ & $10^{-7}$ & $10^{-4}$ \\
$30 \mathrm{Mbps}$ & $10^{-24}$ & $10^{-17}$ & $10^{-11}$ & $10^{-7}$ \\
\hline
\end{tabular}

\section{CONCLUSÕES}

São apresentados alguns indicadores sobre a penetração das redes ópticas de acesso no mercado mundial. Os atributos de capacidade, custo e facilidade de atualização são usados para comparar as principais tecnologias disponíveis para a implantação de infra-estruturas FTTH (Fibra até a residência). É destacado o potencial da alternativa conhecida por WDM-PON (Rede Óptica Passiva usando Multiplexação por Divisão em Comprimento de Onda) como sucessora natural da primeira geração de redes ópticas de acesso hoje em implantação em diversas regiões do mundo. Uma investigação sobre uma PON híbrida TDM-WDM com 32 usuários é relatada. Essa solução combina abundância de largura de faixa e expansibilidade, características de WDMA (acesso múltiplo WDM), com simplicidade e baixos custos inerentes ao TDMA (acesso múltiplo TDM). Os parâmetros de desempenho BER (Taxa de Erro de Bit) e diagrama de olho são usados na determinação do alcance máximo desta rede óptica passiva.

Resultados de simulações para os enlaces ópticos na direção rede-usuário (downstream) com velocidades individuais de 30 e 100 Mbps são apresentados. Constata-se que, para os componentes de rede empregados nas simulações, o alcance máximo é da ordem de $15 \mathrm{~km}$ para uma velocidade de acesso de $30 \mathrm{Mbps}$ e de $10 \mathrm{~km}$ para uma velocidade de acesso de $100 \mathrm{Mbps}$.

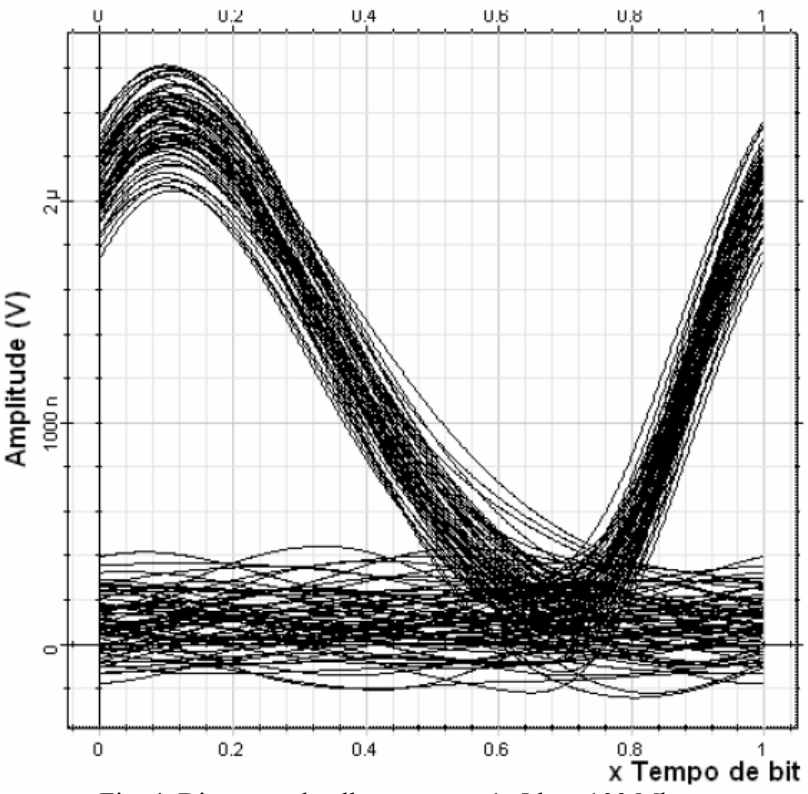

Fig. 4. Diagrama de olho, receptor 1, 5 km, 100 Mbps.

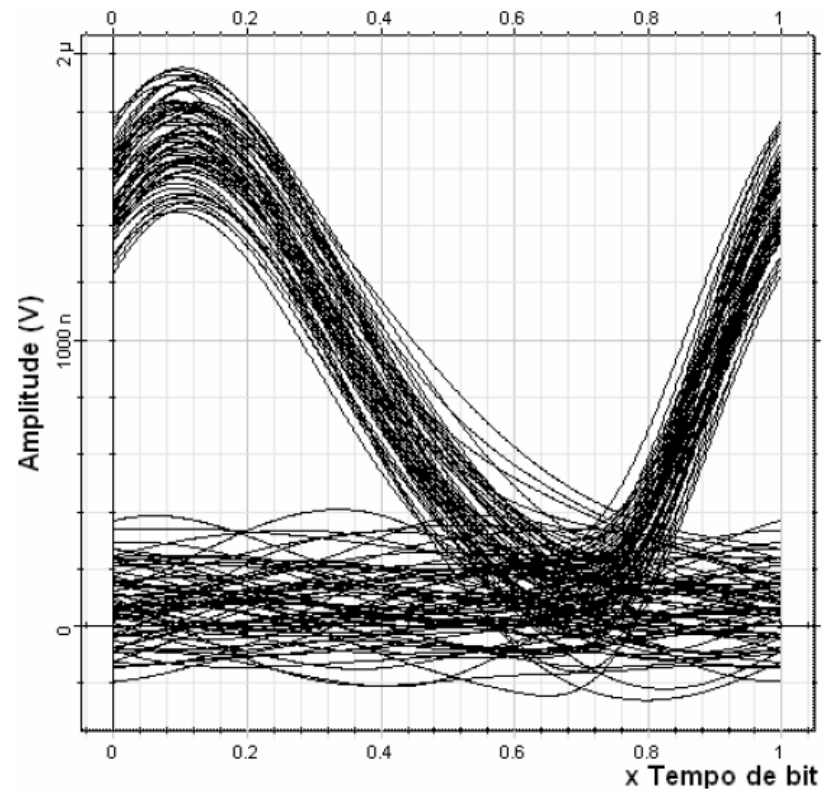

Fig. 5. Diagrama de olho, receptor 1, $10 \mathrm{~km}, 100 \mathrm{Mbps}$. 


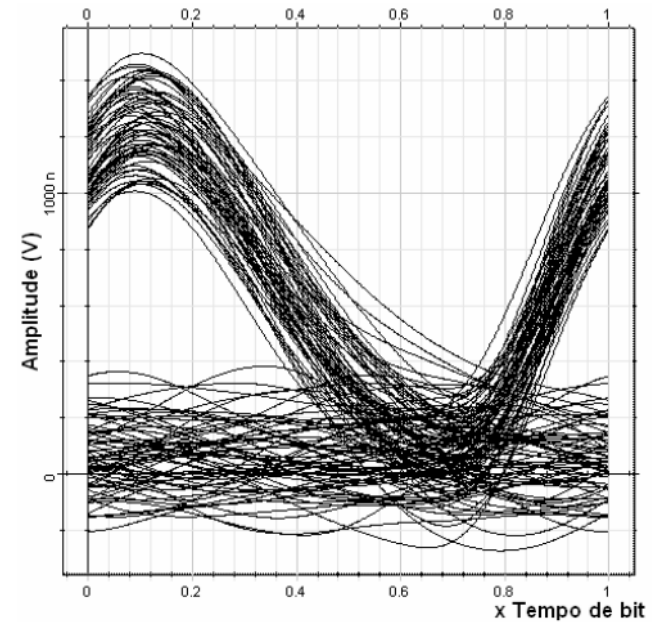

Fig. 6. Diagrama de olho, receptor 1, $15 \mathrm{~km}, 100$ Mbps.

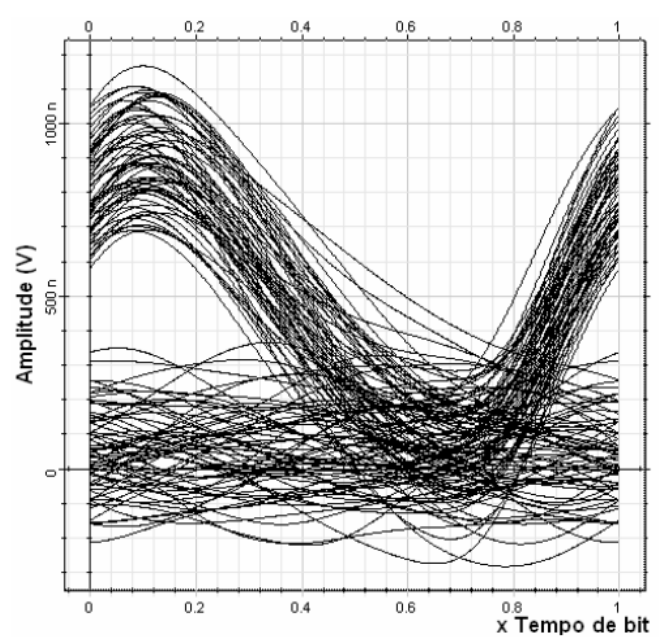

Fig. 7. Diagrama de olho, receptor 1, $20 \mathrm{~km}, 100 \mathrm{Mbps}$.

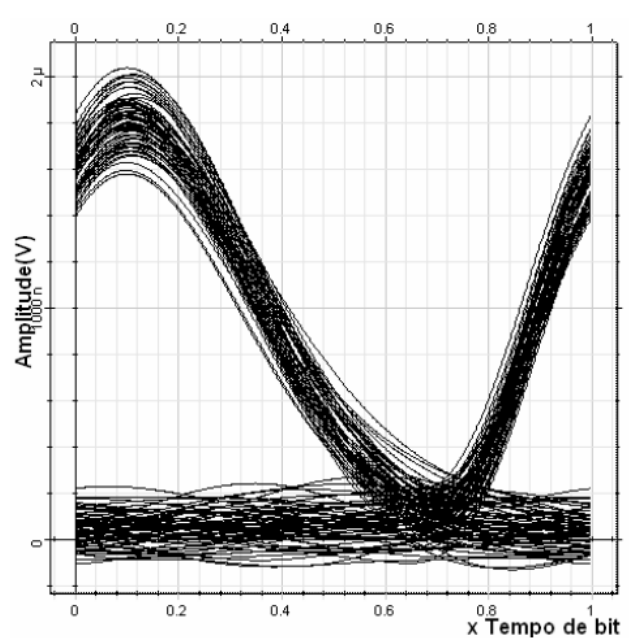

Fig. 8. Diagrama de olho, receptor 1, 5 km, 30 Mbps.

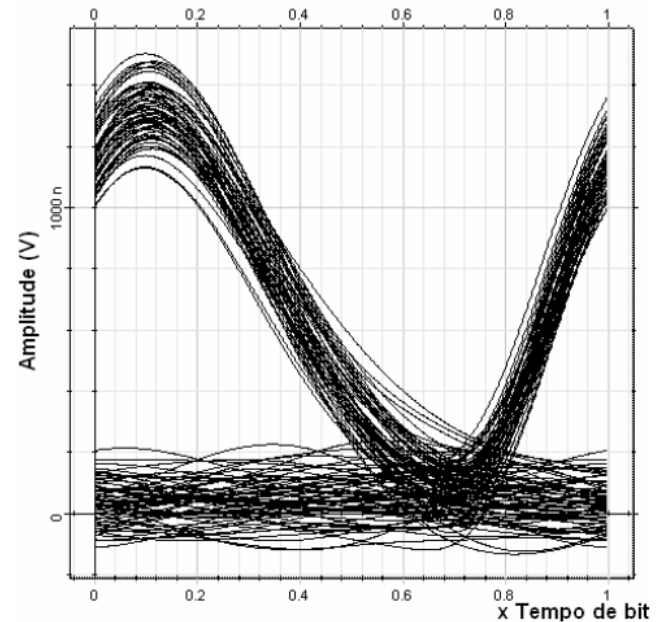

Fig. 9. Diagrama de olho, receptor 1, $10 \mathrm{~km}, 30 \mathrm{Mbps}$.

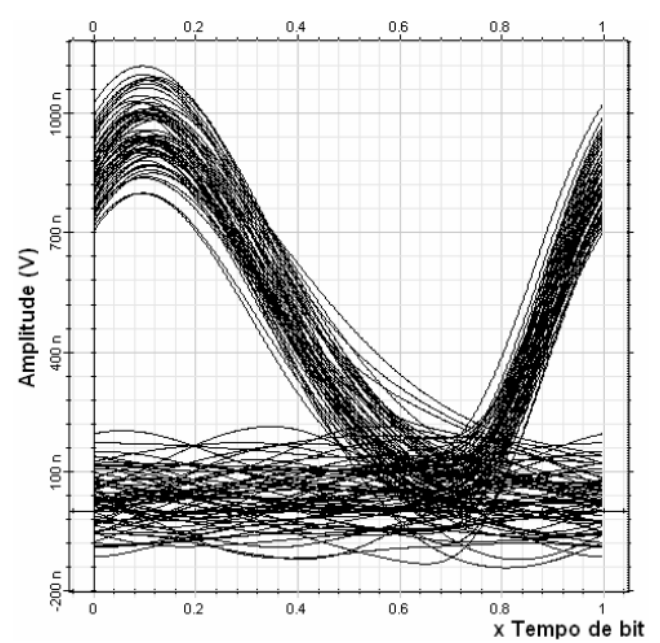

Fig. 10. Diagrama de olho, receptor 1, $15 \mathrm{~km}, 30 \mathrm{Mbps}$.

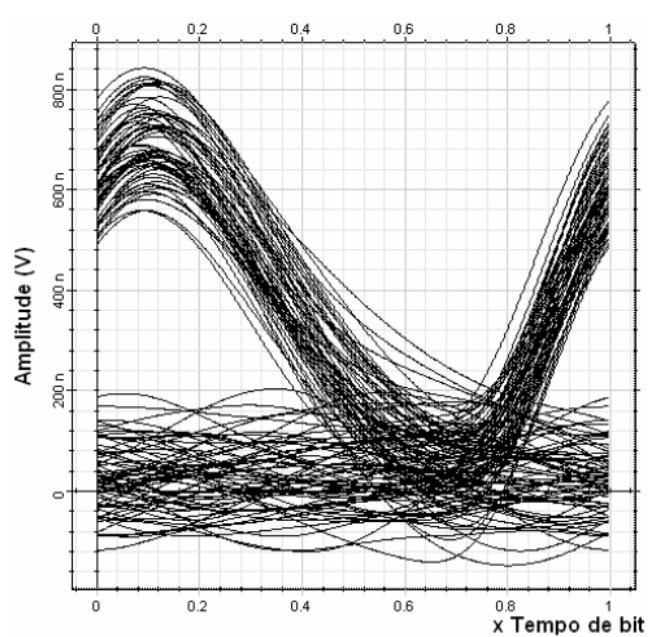

Fig. 11. Diagrama de olho, receptor 1, 20 km, 30 Mbps. 


\section{REFERÊNCIAS}

[1] M. J. O'Mahony, et al, "Future Optical Networks", IEEE/OSA Journal of Lightwave Technology vol. 24, No. 12, pp. 4684-4696, Dezembro 2006.

[2] H. Shinohara, "FTTH experiences in Japan", OSA Journal of Optical Networking, vol. 6., No. 6, pp. 616-623, Junho 2007.

[3] R. Whitman, "The challenges associated with a successful FTTH deployment", Broadband Properties Magazine, vol. 8, No. 9, pp. 52-57, Setembro 2007.

[4] H. Tauber, "Good old Europe at the speed of light?", Fourth Annual FTTH Council Conference, Las Vegas, Nevada, Outubro 2005.

[5] Fiber To The Home Council, "Fibre to the Home Continues its Global March", Press Release, Fevereiro 2009, disponível em www. ftthcouncil.eu.

[6] J. S. Shaik, "FTTH Deployment Options for Telecom Operators", Sterlite Optical Techologies Ltd., Abril 2008, disponível em www.sterliteoptical.com.

[7] J. E. P. de Farias, "Introdução às Redes Ethernet Ópticas Passivas", Anais do NETCOM 2007, São Paulo, 2007.

[8] D. Kettler, et al, "Driving fiber to the home", IEEE Communications Magazine, vol. 38, No. 11, pp. 106-110, Novembro 2000.

[9] F. J. Effenberger, et al, "Advances in broadband passive optical networking technologies", IEEE Communications Magazine, vol. 39, No. 12, pp. 118-124, Dezembro 2001.

[10] M. Hajduczenia, H. J. A. da Silva e P. Monteiro, "EPON versus APON and GPON: a detailed performance comparison", OSA Journal of Optical Networking, vol. 5., No. 4, pp. 298-319, Abril 2006.

[11] M. Hajduczenia, et al, "Optimized passive optical network deployment", OSA Journal of Optical Networking, vol. 6., No. 9, pp. 1079-1104, Setembro 2007.

[12] M. P. McGarry, M. Reisslein e M. Maier, "WDM Ethernet Passive Optical Networks", IEEE Communications Magazine, vol. 44, No. 2, pp. S19-S25, Fevereiro 2006

[13] A. Banerjee, et al, "WDM-PON Technologies for broadband access: a review", OSA Journal of Optical Networking, vol. 4., No. 11, pp. 737758, Novembro 2005.

[14] L. G. Kazovsky, et al, "Next-Generation Optical Access Networks", IEEE/OSA Journal of Lightwave Technology, vol. 25, No. 11, pp. 34283442, Novembro 2007.

[15] R. Lin, "Next-Generation PON in Emerging Networks", Anais da IEEE/OSA OFC/NFOEC 2008, paper OWH1, Março 2008.

[16] S. Gorshe e J. Mandin, "Introduction to IEEE 802.3av 10Gbit/s Ethernet Passive Optical Networks (10G EPON)", PMC-Sierra White Paper, PMC-2081212, Issue 1, Janeiro 2009. 